\title{
Inter- and Intra-annular Proton Exchange in Gaseous Benzylbenzenium Ions (Protonated Diphenylmethane) $\dagger$
}

Dietmar Kuck $\ddagger$ and Wolfgang Bäther§

Fakultät für Chemie, Universität Bielefeld, Universitätsstraße, D-4800 Bielefeld, FRG

\begin{abstract}
Two distinct proton exchange reactions occur in metastable gaseous benzylbenzenium ions, generated by isobutane chemical ionization of diphenylmethane and four deuterium-labelled analogues. Whereas the proton ring-walk at the benzenium moiety is fast giving rise to a completely random intraannular proton exchange, the interannular proton exchange is surprisingly slow and competes with the elimination of benzene. A kinetic isotope effect of $k_{\mathrm{H}} / k_{\mathrm{D}}=5$ has been determined for the interannular proton transfer, and a particularly high energy barrier of $50-75 \mathrm{~kJ} \mathrm{~mol}^{-1}$ has been estimated. These observations are attributed to steric restrictions of the ring-to-ring proton transfer in benzylbenzenium ions and contrasted to the fast interannular proton exchange in the higher homologues.
\end{abstract}

\section{INTRODUCTION}

Proton rearrangement reactions are well known for occurring in arenium ions, ${ }^{1-3}$ the key intermediates in electrophilic aromatic substitution. They can induce shift or loss of a substituent or isotopic label at the aromatic ring and are, therefore, of great interest for both synthetic and mechanistic aspects. In the gas phase, proton exchange processes occur by both intramolecular proton (or hydride) shifts $^{4-7}$ and by intermolecular proton transfer. ${ }^{8}$

We have studied the intramolecular isomerization reactions of various benzenium ions in the gas phase ${ }^{5-7,9}$ Among these, ( $\omega$-phenylalkyl)-benzenium ions with $2 \leq \omega \leq 20$ methylene groups in the aliphatic chain (e.g. 2, Eqn (1)) undergo a complete interchange of the eleven protons at the aromatic rings within $<10^{-5}$ s. $^{7 \mathrm{a}, \mathrm{b}} \mathrm{A}$ similarly fast interannular (ring-to-ring) proton transfer has been found in protonated tri- and tetrabenzylmethane, where up to 21 protons are involved in the exchange. ${ }^{5}$

$$
\begin{aligned}
& { }_{\mathrm{H}}^{\mathrm{H}} \rightarrow-\left(\mathrm{CH}_{2}\right)_{\mathrm{U}}-\mathrm{O}=\left\langle\mathrm{O}-\left(\mathrm{CH}_{2}\right)_{\mathrm{U}}-\mathrm{X}_{\mathrm{H}}^{\mathrm{H}}\right. \\
& 1 \omega=1 \\
& 2 \omega=2 \\
& \text { land toutomers) }
\end{aligned}
$$

In this contribution, we report on the proton exchange in the lower homologue of 2 , i.e. benzylbenzenium ions 1 (Eqn (1)). These ions have been found to exhibit a particular isomerization behaviour and both the inter- and the intraannular proton exchange have been discerned experimentally. In addition, the chemistry of ions $\mathbf{1}$ is of more general

$\dagger$ Dedicated to Professor Dr Tino Gäumann on the occasion of his 60th birthday.

$\ddagger$ Author to whom correspondence should be addressed.

\$ New address: Drägerwerke A.G., D-2400 Lübeck, FRG. interest since benzylbenzenium-type ions have been proposed as intermediates in ion-molecule reactions of benzyl cations and neutral toluene in radiolysis ${ }^{10 a}$ and ICR experiments. ${ }^{10 \mathrm{~b}}$ This reaction (Eqn (2)) has been used to distinguish between the benzyl and the tropylium structures of $\left[\mathrm{C}_{7} \mathrm{H}_{7}\right]^{+}$ions. ${ }^{10}$ Although a ring-to-ring proton transfer step has been implied by the authors, ${ }^{10 a, b}$ the extent of an eventual interannular proton exchange has not been considered.

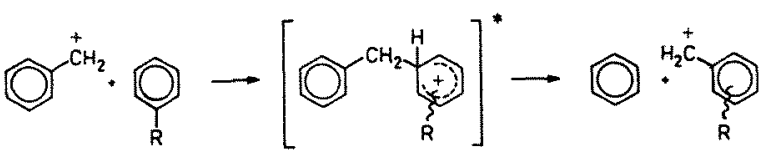

\section{RESULTS AND DISCUSSION}

Benzylbenzenium ions 1 and 1a-1d have been generated by chemical ionization (CI) of diphenylmethane 3 and site-specifically deuterated analogues 3a-3d, respectively, using isobutane as reagent gas. The CI mass spectra of 3 and 1,2-diphenylethane 4 are contrasted in Table 1, together with the partial CI mass spectra of their ring- $d_{5}$ labelled analogues $3 a$ and 4a. ${ }^{\text {b }}$

It is evident from the relative abundances of the $[\mathrm{M}+\mathrm{H}]^{+}$ions $\uparrow$ that ions $\mathbf{1}$ are considerably less stable than ions 2 (as well as their long-chain homologues $\left.^{7 \mathrm{a}, \mathrm{b}}\right)$. As found for all ( $\omega$-phenylalkyl)benzenium ions, loss of benzene is by far the dominant fragmentation channel (Eqn (3a)). However, the $\left[\mathrm{C}_{7} \mathrm{H}_{7}\right]^{+}$fragment ions may be formed in part from the radical cations $3^{+\cdot}$ generated in the

IT The difference in the abundance ratios $[\mathrm{M}+\mathrm{H}]^{+} /[\mathrm{M}+\mathrm{H}-$ $\left.\mathrm{C}_{6} \mathrm{H}_{6}\right]^{+}$(Table 1) for ions 1 and 2 has been found to be roughly independent of the type of the CI source used (see Experimental). 
3

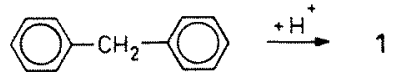

30

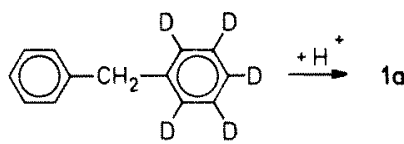

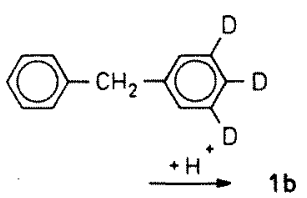

plasma of the CI source (Eqn (3b)). Thus, deuterium labelling gives no unequivocal information on the proton exchange in ions 1 fragmentating in the ion source of the mass spectrometer. Nevertheless, a striking difference is evident from the CI mass spectra of the labelled analogues (Table 1): whereas protonated 4a (ions 2a) eliminate all of the possible $\mathrm{C}_{6}(\mathrm{H}, \mathrm{D})_{6}$ isotopomers, the protonated diphenylmethane 3a (ions 1a) yields almost exclusively $\left[\mathrm{C}_{7} \mathrm{H}_{7}\right]^{+}$ $(m / z 91)$ and $\left[\mathrm{C}_{7} \mathrm{H}_{2} \mathrm{D}_{5}\right]^{+}(m / z 96)$. Assuming these ions to be formed from ions 1a only, it follows that the interannular proton exchange is suppressed completely in short-lived benzylbenzenium ions.

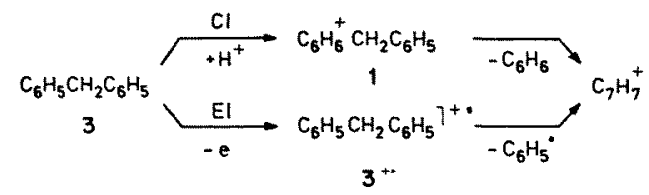

Contrary to the 'normal' CI mass spectrum, the mass-analysed ion kinetic energy (MIKE) spectrum of ions 1 consists of $\left[\mathrm{C}_{7} \mathrm{H}_{7}\right]^{+}$exclusively, originating

Table 1. Partiala, ${ }^{a, b}$ CI(isobutane) mass spectra of diphenylmethane (3) and 1,2-diphenylethane (4) and their ring- $d_{5}$ analogues $3 a$ and $4 a$

\begin{tabular}{|c|c|c|c|c|}
\hline \multirow[b]{2}{*}{ Assignment } & \multicolumn{2}{|c|}{$3^{\mathbf{b}}$} & \multicolumn{2}{|c|}{$4^{b}$} \\
\hline & $m / z$ & $(\% \mathrm{~B})$ & $\mathrm{m} / \mathrm{z}$ & $(\% \mathrm{~B})$ \\
\hline$\left[\mathrm{M}+\mathrm{C}_{4} \mathrm{H}_{9}\right]^{+}$ & 225 & 0.6 & 239 & 3.5 \\
\hline$\left[\mathrm{M}+\mathrm{C}_{3} \mathrm{H}_{7}\right]^{+}$ & 211 & 0.05 & 225 & 10.1 \\
\hline$[\mathrm{M}+\mathrm{H}]^{+}$ & 169 & 2.4 & 183 & 23.4 \\
\hline$[\mathrm{M}]^{+*}$ & 168 & 49.4 & 182 & 41.6 \\
\hline$[\mathbf{M}-\mathbf{H}]^{+}$ & 167 & 21.2 & 181 & 51.4 \\
\hline \multirow{4}{*}{$\left.\begin{array}{l}{\left[\mathrm{M}+\mathrm{C}_{4} \mathrm{H}_{9}-\mathrm{C}_{6} \mathrm{H}_{6}\right]^{+}} \\
{\left[\mathrm{M}+\mathrm{C}_{3} \mathrm{H}_{7}-\mathrm{C}_{6} \mathrm{H}_{6}\right]^{+}} \\
{\left[\mathrm{M}+\mathrm{H}-\mathrm{C}_{6} \mathrm{H}_{6}\right]^{+}} \\
{\left[\mathrm{C}_{7} \mathrm{H}_{7}\right]^{+}}\end{array}\right\}$} & 147 & 1.2 & 161 & 0.7 \\
\hline & 133 & 4.3 & 147 & 15.4 \\
\hline & 91 & 100.0 & $\begin{array}{r}105 \\
91\end{array}$ & $\begin{array}{r}100.0 \\
28 ?\end{array}$ \\
\hline & \multicolumn{2}{|c|}{$3 a^{b, c}$} & \multicolumn{2}{|c|}{$4 \mathrm{a}^{\mathrm{b}, \mathrm{c}}$} \\
\hline$\left[\mathrm{M}+\mathrm{H}-\mathrm{C}_{6} \mathrm{H}_{6}\right]^{+}$ & 96 & 93.3 & 110 & 3.1 \\
\hline$\left[\mathrm{M}+\mathrm{H}-\mathrm{C}_{6} \mathrm{H}_{5} \mathrm{D}\right]^{+}$ & 95 & 7.6 & 109 & 10.9 \\
\hline$\left[\mathrm{M}+\mathrm{H}-\mathrm{C}_{6} \mathrm{H}_{4} \mathrm{D}_{2}\right]^{+}$ & 94 & 0.8 & 108 & 29.7 \\
\hline$\left[\mathrm{M}+\mathrm{H}-\mathrm{C}_{6} \mathrm{H}_{3} \mathrm{D}_{3}\right]^{+}$ & 93 & 0.9 & 107 & 36.6 \\
\hline$\left[\mathrm{M}+\mathrm{H}-\mathrm{C}_{6} \mathrm{H}_{2} \mathrm{D}_{4}\right]^{+}$ & 92 & 1.4 & 106 & 15.0 \\
\hline$\left[\mathrm{M}+\mathrm{H}-\mathrm{C}_{6} \mathrm{HD}_{5}\right]^{+}$ & 91 & 100.0 & 105 & 4.7 \\
\hline
\end{tabular}

a Peaks of $\leq 5 \% \mathrm{~B}$ other than those listed have been ignored.

Values corrected for natural abundance of ${ }^{13} \mathrm{C}$.

- Values not corrected for incomplete D labelling.
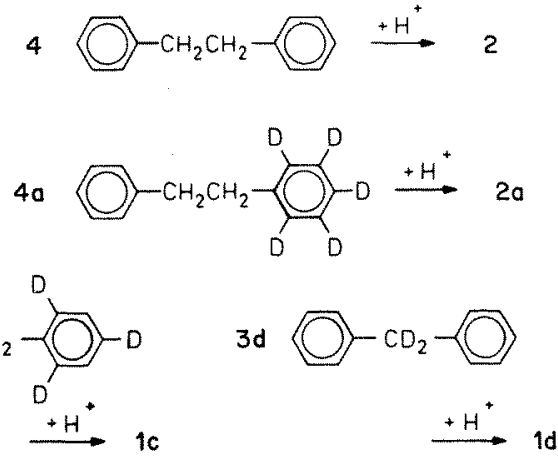

unequivocally from these very precursor ions. Since the reaction $3^{+\cdot} \rightarrow\left[\mathrm{C}_{7} \mathrm{H}_{7}\right]^{+}$(Eqn (3b)) does not occur from metastable ions, ${ }^{11}$ contributions due to isobaric radical cations $\left[\left({ }^{13} \mathrm{C}_{1}\right)-3\right]^{+\cdot}$ do not have to be considered. Furthermore, the mean lifetime of metastable ions is relatively long $\left(\sim 2 \times 10^{-5} \mathrm{~s}\right.$ for 1 and 2 fragmenting in the second field-free region (FFR) of a ZAB-2F instrument ${ }^{12}$ ) due to their small excess energies. ${ }^{13}$ For this reason, the intramolecular competition of isomerization and fragmentation is reflected best in metastable ions.

Similar to the CI mass spectra, the MIKE spectra of the ring- $d_{5}$ labelled ions 1a and 2a exhibit surprisingly different distributions for loss of benzene isotopomers (Fig. 1). The relative abundances of the $[\mathrm{M}+\mathrm{H}-$ $\left.\mathrm{C}_{6}(\mathrm{H}, \mathrm{D})_{6}\right]^{+}$ions from ions $2 \mathrm{a}$ agree perfectly with the pattern calculated for the random interchange of the eleven protons and deuterons at the aromatic rings, ${ }^{7 a, b}$ whereas those from ions 1a compose a far different, concave and unsymmetrical pattern (Table 2).

Obviously, the interannular proton exchange in benzylbenzenium ions 1 is much slower than in the higher homologues, the two benzene rings thus retaining their identities. This result is in agreement with the very slow proton exchange found in the CI mass spectra of dibenzyl ether, ${ }^{14}$ corroborating the benzylbenzenium-type structure proposed for the loss of water (Eqn (4)) ${ }^{14}$ Correspondingly, the ring- $d_{3}$ labelled ions 1b and 1c also exhibit a concave pattern for the loss of benzene isotopomers. As in the case of ions 1a, the two benzene rings are eliminated with different relative rates, in contrast to ions 2 a. Obviously, the interannular transfer of a proton is faster than that of a deuteron, leading to the observed preference for loss of the deuterated benzenes. This kinetic isotope effect $\dagger$ indicates that, contrary to 2 and the long-chain ( $\omega$-phenylalkyl)-benzenium ions, the interannular proton exchange competes with the elimination of benzene in benzylbenzenium ions 1 .

$$
\mathrm{C}_{6} \mathrm{H}_{5} \mathrm{CH}_{2} \mathrm{OCH}_{2} \mathrm{C}_{6} \mathrm{H}_{5} \stackrel{+\mathrm{H}^{+}}{\longrightarrow}\left(0-\mathrm{HOCH}_{2} \mathrm{C}_{6} \mathrm{H}_{5}^{+} \mathrm{CH}_{2} \mathrm{C}_{6} \mathrm{H}_{5} \longrightarrow \mathrm{C}_{14} \mathrm{H}_{13}^{+}+\mathrm{H}_{2} \mathrm{O}\right.
$$

In contrast to the interannular proton exchange, the intra-annular proton exchange in ions 1 is still much faster than fragmentation, as might have been anticipated for this 'ring-walk' isomerization ubiquitous in simpler gaseous benzenium ions. ${ }^{4,6}$ This

$\dagger$ The possibility of an equilibrium isotope effect on the protonation of the deuterated diphenylmethanes has been considered but rejected; unfortunately, the proton affinity of deuterated benzene has not been determined, (to our knowledge). 


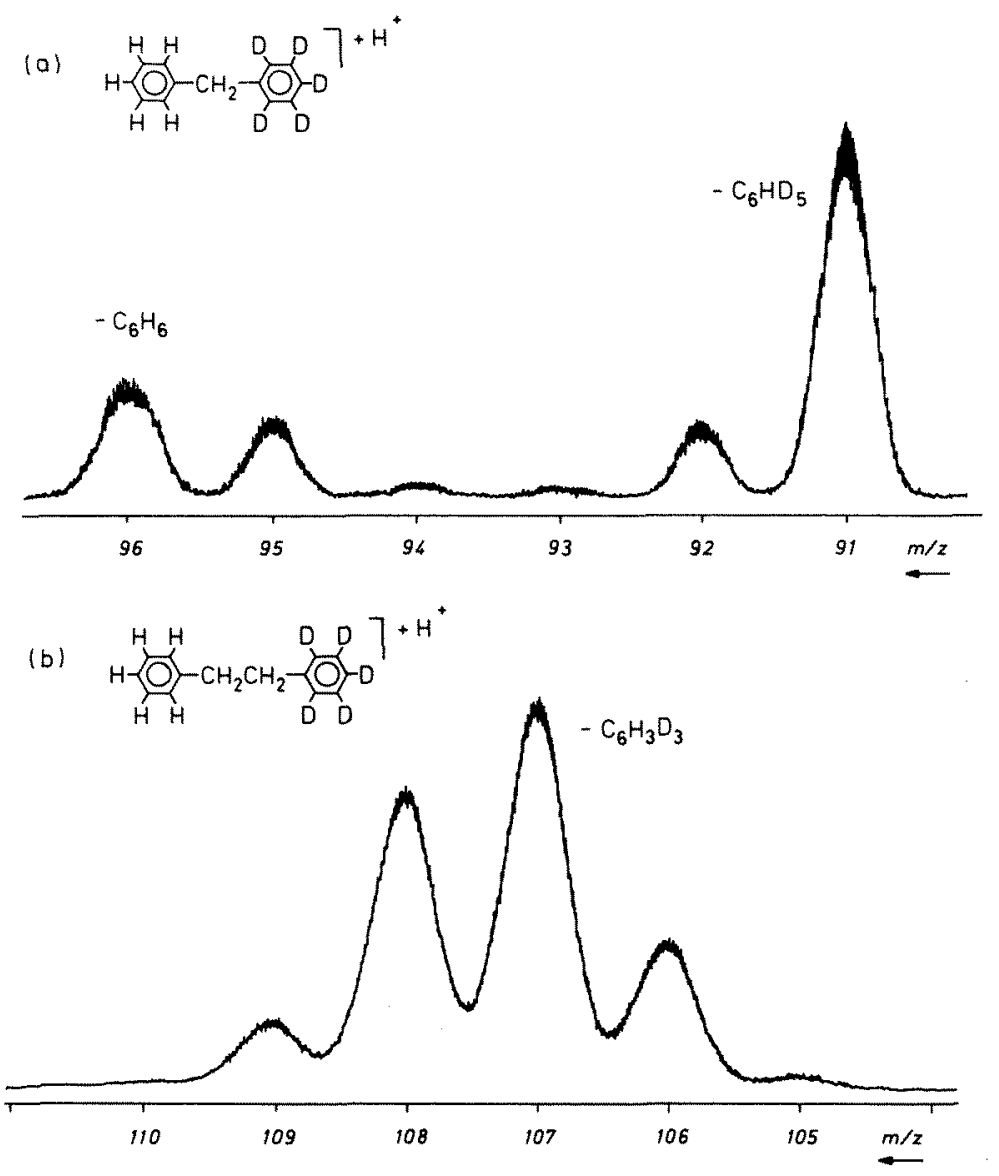

Figure 1. MIKE spectra of protonated ring- $d_{5}$ labelled diphenylmethane $[3 a+H]^{+}=1 \mathrm{a}(\mathrm{a})$ and 1,2 -diphenylethane $[4 \mathbf{a}+\mathrm{H}]^{+}=\mathbf{2 a}(\mathrm{b})$.

follows from the MIKE spectra of the site-specifically labelled ions $1 \mathbf{b}$ and $1 \mathbf{c}$, which are identical within the limits of experimental error (Table 2). In spite of the relatively low energy required for loss of benzene from ions 1 (vide infra), the activation barriers towards the intra-annular proton ring-walk are still low enough to allow this process to achieve the random distribution of the six hydrogen atoms at the protonated ring. The simultaneous occurrence of the intra- and the interannular proton exchange, suggested in previous papers,${ }^{7 a, b}$ has been proven here for the first time, taking advantage of the slowness of the latter process in ions 1 . The interplay of both is illustrated in Scheme 1.

Table 2. Loss of benzene isotopmers ${ }^{\mathrm{a}}$ from labelled benzylbenzenium ions $1 \mathrm{a}-1 \mathrm{~d}$ in the 2 nd field-free region

$\begin{array}{llrrrrrr}\text { Ion } & & \mathrm{C}_{6} \mathrm{H}_{6} & \mathrm{C}_{6} \mathrm{H}_{5} \mathrm{D} & \mathrm{C}_{6} \mathrm{H}_{4} \mathrm{D}_{2} & \mathrm{C}_{6} \mathrm{H}_{3} \mathrm{D}_{3} & \mathrm{C}_{6} \mathrm{H}_{2} \mathrm{D}_{4} & \mathrm{C}_{6} \mathrm{HD}_{5} \\ 1 \mathrm{a} & \text { obs. } & 18.8 & 12.1 & 1.2 & 1.0 & 11.8 & 55.1 \\ 2 \mathrm{a} & \text { obs. } & 0.2 & 6.6 & 32.8 & 43.0 & 16.0 & 1.4 \\ 1 \mathrm{a}, 2 \mathrm{2a} & \text { stat. }^{\mathrm{c}} & 0.2 & 6.5 & 32.5 & 43.3 & 16.2 & 1.3 \\ \text { 1b } & \text { obs. } & 32.5 & 8.0 & 7.5 & 52.0 & - & - \\ \text { 1c } & \text { obs. } & 32.0 & 7.5 & 7.2 & 53.4 & - & - \\ \text { 1d } & \text { obs. } & 97.5 & 2.5 & - & - & - & -\end{array}$

In $\% \sum$; exp. error $\pm 10 \%$ (rel.) for low values.

b Taken from Ref. 7b.

c Calculated for the complete interchange of six $\mathrm{H}^{+}$and five $\mathrm{D}^{+}$ at the aromatic rings.
Skeletal rearrangement reactions of ions 1 , e.g. electrophilic attack of the protonated benzene ring at the unprotonated one, do not occur. This type of isomerization, playing an important role in the radical cations of diphenylmethane and its derivatives, ${ }^{11}$ should give rise to scrambling of the label at the methylene group of ions 1d, which is found to be a very minor process (Table 2).

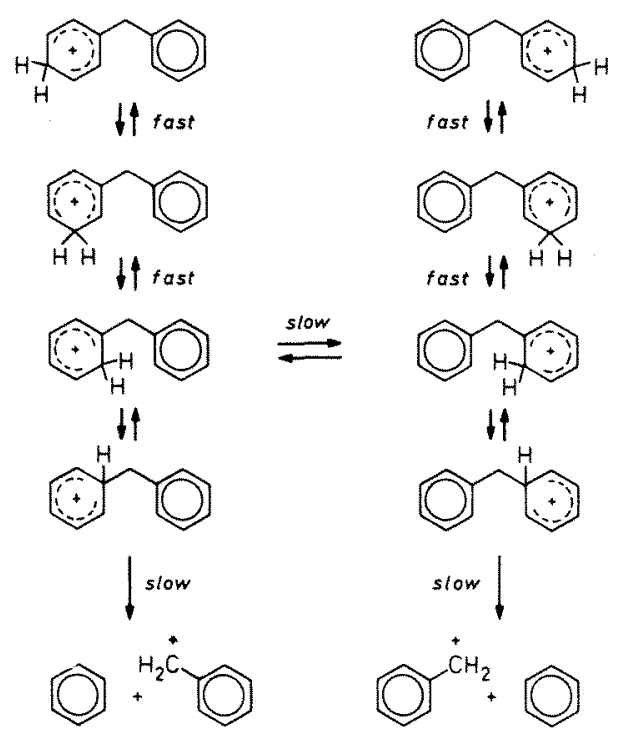

Scheme 1. 


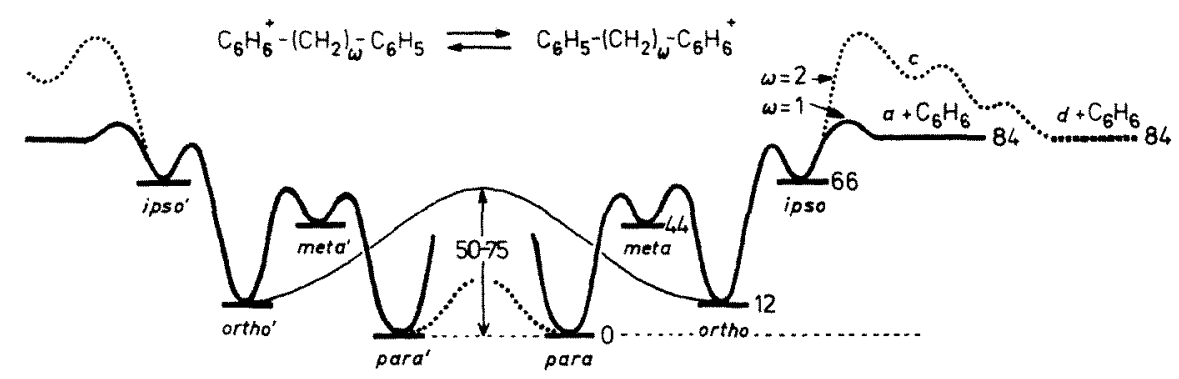

Figure 2. Energy profiles for the proton exchange in benzylbenzenium ions $1(\omega=1)$ and $(\beta$-phenylethyl)-benzenium ions $2(\omega=2)$. The energy values (in $\mathrm{kJ} \mathrm{mol}^{-1}$ ) refer to the heats of formation of the tautomers ipso-1 and ipso-2, respectively. ${ }^{17-19}$ For fragmentation products $a$ and $b$, see Scheme 2 .

The particular behaviour of ions 1 , as compared to ions 2 and all homologues, can be explained by an increase in the isomerization barrier concomitant with a decrease in the fragmentation barrier, giving rise to thresholds of similar heights (Fig. 2). In this way, both the ring-to-ring proton transfer and the heterolytic cleavage of the $\mathrm{C}^{\alpha}-\mathrm{C}^{i p s o}$ bonds become ratedetermining and the primary kinetic isotope effect on the interannular proton transfer, $k_{\mathrm{H}} / k_{\mathrm{D}}=5$ (vide infra), appears.

The increase of the barrier towards interannular proton transfer is attributed to steric and entropic reasons. From an inspection of molecular models it follows that in ions 2 this process can take place through linear or near-linear $[\mathrm{C} \cdots \mathrm{H} \cdots \mathrm{C}]$ transition state geometries. Mutual transfer is possible, without appreciable torsion of $\mathrm{C}-\mathrm{C}$ bonds, between all of the six meta and para positions; the same is true for mutual transfer between the four ortho positions of ions 2 . (In the higher homologues of 2 , even this restriction breaks down.)

In contrast, the short methylene link in ions 1 excludes the meta and para positions from the interannular proton exchange. Proton transfer between two ortho positions is sterically possible but requires a bent transition state geometry $\left(\Varangle[\mathrm{C} \cdots \mathrm{H} \cdots \mathrm{C}] \approx 140^{\circ}\right)$; proton transfer involving an ipso position requires even stronger deviation from the energetically most favourable linear transition state. ${ }^{15}$ Thus, the interannular proton exchange in ions 1 appears to be retarded by statistical and energetic restrictions of the proton transfer channel.
In addition, the elimination of benzene from ions 1 is much more facile than from ions 2 (and the higher homologues). This is evident from the particularly low relative abundance of $[\mathrm{M}+\mathrm{H}]^{+}$ions 1 in the $\mathrm{CI}$ mass spectrum (Table 1). The cleavage of the ipso tautomers of ions 1 yields directly a stable fragment ion, viz. the benzyl cation $a$ (Scheme 2 ). In the case of ions 2 , the incipient $\beta$-phenylethyl ion $b$ has been assumed to be unstable ${ }^{16,9 a}$ and to undergo an isomerization to, for example, ions $d$ via a series of unimolecularly formed ion-molecule complexes, inter alia $c^{9 \mathrm{a}}$ (Scheme 2). Unfortunately, the experimental determination of the critical energy for the loss of benzene from ions 1 is not possible (generation of ions 1 by electron impact (EI) methods proved to be unsuccessful in contrast to ions 2; Ref. 7a). From thermochemical values, ${ }^{17} \mathrm{a}$ barrier of $\sim 85 \mathrm{~kJ} \mathrm{~mol}^{-1}$ is calculated, assuming no significant reverse critical energy. $\dagger$ For ions 2 , a value of $\sim 125 \mathrm{~kJ} \mathrm{~mol}^{-1}$ can be deduced on the basis of appearance energy measurements performed with 2-type ions $s^{9 a}$ (Fig. 2).

It is of interest to consider the energetic details of the intraannular proton exchange in ions 1 in more detail. For this purpose, the relative heats of formation of the four tautomeric toluenium ions have been adopted, as computed by Heidrich and coworkers, ${ }^{18}$ to estimate the values of the corresponding tautomers of ions 1 . In spite of some uncertainty in the relative heats of formation, ${ }^{19}$ the energy

$\dagger$ Note that for both ions $\mathbf{1}$ and $\mathbf{2}$ the peak shapes are narrow and near-Gaussian (cf. Fig. 2).

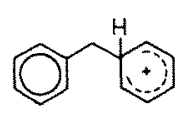

ipso-1

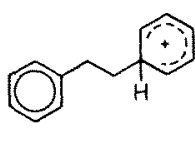

ipso- 2

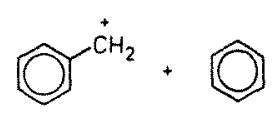

0

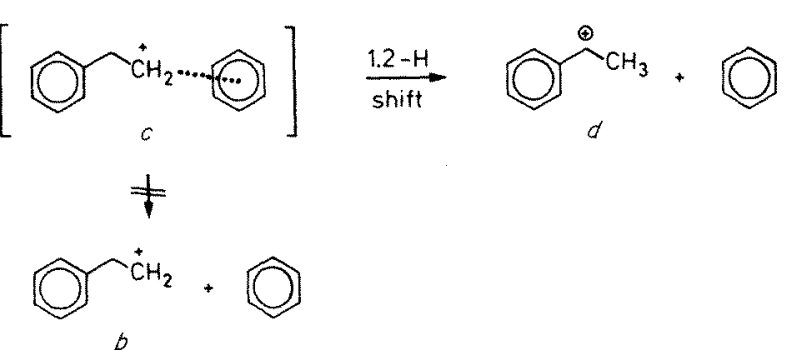

Scheme 2. 
profile thus emerging enables some semiquantitative deductions.

Firstly, the ipso tautomer of ions 1 (ipso-1) is energetically much closer to that of the pair of fragments than ipso-2, increasing the chance for ipso-1 to escape from the ring-walk. The relatively high reactivity of ipso-1 is reflected in the low abundance of ions 1 in the CI mass spectrum of 3 .

Secondly, the threshold of the ring-to-ring proton transfer in ions 1 exceeds that for formation of the meta-1 tautomers. This is because an ortho-1 tautomer equilibrates with the corresponding meta-1 tautomers by fast ring-walk, but not with the ortho' -1 tautomers. Although the barriers towards intra- and interannular proton transfer are difficult to compare due to their different features, the threshold of the ring-to-ring proton transfer is estimated to be in the range of $50-75 \mathrm{~kJ} \mathrm{~mol}^{-1}$ above the level of the lowest-energy tautomers, i.e. para-1. Hence, the barrier towards the actual transfer step from an ortho to an ortho' position is in the range of $40-65 \mathrm{~kJ} \mathrm{~mol}^{-1}$ (Fig. 2).

Thirdly, the distinct observation of the intraannular proton along with the interannular proton exchange permits the conclusion that in protonated $\alpha, \omega$ diphenylalkanes, e.g. ions 2 , and oligophenylalkanes both processes contribute to the extremely fast overall proton interchange.

Kinetic model calculations ${ }^{7 b, 12}$ for ions 2 and the higher protonated $\alpha, \omega$-diphenylalkanes have shown that the rate constant of the interannular proton transfer in the metastable ions is $k_{\mathrm{H}} \sim k_{\mathrm{D}} \geq 1 \times$ $10^{6} \mathrm{~s}^{-1}$. The mean rate constant of fragmentation $\left(k_{\mathrm{f}}\right)$ of these ions in the instrument used is in the range of $1 \times 10^{5} \mathrm{~s}^{-1} \geq k_{\mathrm{f}} \geq 5 \times 10^{4} \mathrm{~s}^{-1}$, depending on the mass of the ions studied. The ratio of $k_{\mathrm{H}} / k_{\mathrm{f}} \geq 20$ explains the completely random distribution of the eleven protons at the aromatic rings in ions 2 and the higher homologues. Lower $k_{\mathrm{H}}$ and $k_{\mathrm{D}}$ values yield concave patterns for loss of benzene isotopomers. ${ }^{7 \mathrm{~b}}$
Table 3. Loss of $\mathrm{C}_{6}(\mathrm{H}, \mathrm{D})_{6}$ from metastable ions $2 \mathrm{a}$ (2nd FFR) calculated by the kinetic model $(\% \Sigma)^{7 \mathrm{~b}}$

$\begin{array}{lcccccc}\text { Loss of } & \mathrm{C}_{6} \mathrm{H}_{6} & \mathrm{C}_{6} \mathrm{H}_{5} \mathrm{D} & \mathrm{C}_{6} \mathrm{H}_{4} \mathrm{D}_{2} & \mathrm{C}_{6} \mathrm{H}_{3} \mathrm{D}_{3} & \mathrm{C}_{6} \mathrm{H}_{2} \mathrm{D}_{4} & \mathrm{C}_{6} \mathrm{HD}_{5} \\ \text { Exp. } & 18.8 & 12.1 & 1.2 & 1.0 & 11.8 & 55.1 \\ \text { Calc. } & 18.0 & 11.5 & 1.8 & 1.1 & 11.9 & 55.7\end{array}$

${ }^{\mathrm{a}} k_{\mathrm{H}}=5 \times 10^{5} \mathrm{~s}^{-1} ; k_{\mathrm{D}}=1 \times 10^{5} \mathrm{~s}^{-1} ; k_{\mathrm{f}}=8 \times 10^{4} \mathrm{~s}^{-1}$.

Similar calculations have been carried out for the ring- $d_{5}$ labelled benzylbenzenium ions 1a. The asymmetric pattern observed for the metastable ions can be simulated by assuming a primary isotope effect of $k_{\mathrm{H}} / k_{\mathrm{D}}=5$ operating during the interannular transfer steps. The closest agreement to the experimental abundance distribution has been obtained with $k_{\mathrm{H}}=5 \times 10^{5} \mathrm{~s}^{-1}, \quad k_{\mathrm{D}}=1 \times 10^{5} \mathrm{~s}^{-1}$ and $k_{\mathrm{f}}=8 \times 10^{4} \mathrm{~s}^{-1}$ (Table 3). Using these values, Fig. 3 has been computed showing the variation of the pattern with the lifetime of ions 1a. The pattern corresponding to representative metastable ions is relieved and compared to the experimental values in Table 3.

Although the results afford only a rough kinetic picture, they corroborate the conclusion that the interannular proton transfer and the elimination of benzene are competing reaction channels in long-lived benzylbenzenium ions 1 . Secondary isotope effects need not be considered in order to explain the observations. The primary isotope effect in the range of $k_{\mathrm{H}} / k_{\mathrm{D}}=5$ has been found also for interannular proton transfer in protonated 1,4-diphenyl-but-2-yne. Similar to ions 1, this species exhibits a sterically hindered ring-to-ring proton exchange, probably involving energetically unfavourable tautomers. A competition ratio of $k_{\mathrm{H}} / k_{\mathrm{f}}=1$ has been evaluated for this system ${ }^{7 \mathrm{~b}}$ which is even lower than that obtained in the present work for protonated diphenylmethane, viz. $k_{\mathrm{H}} / k_{\mathrm{f}} \sim 6$.

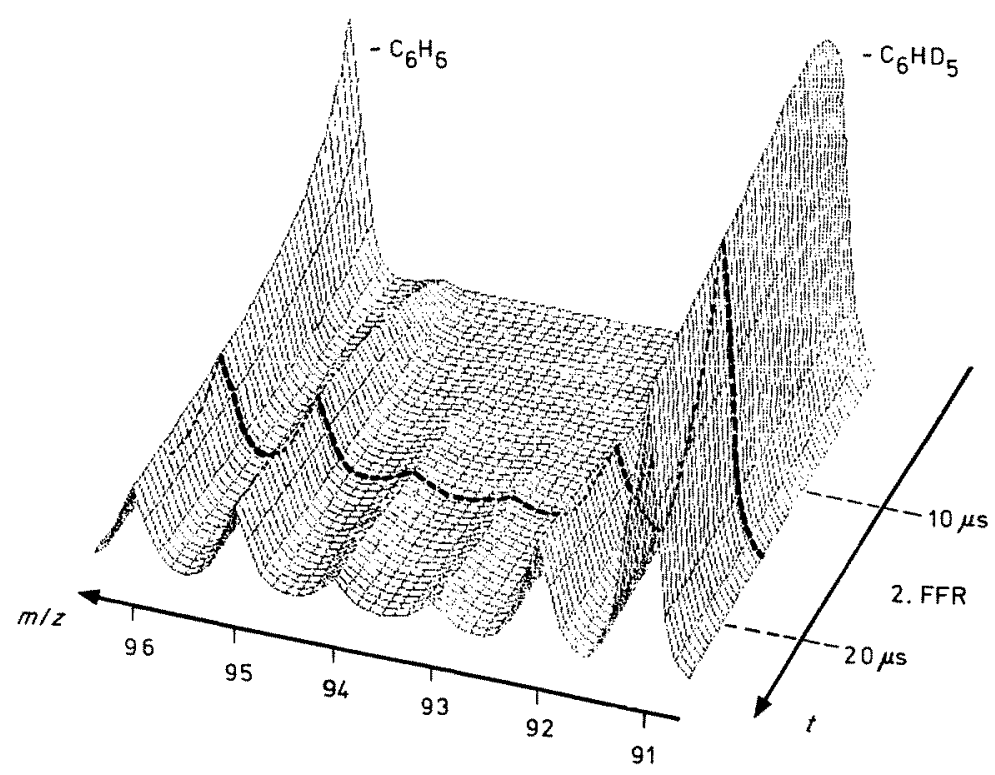

Figure 3. Relative abundances of benzene isotopmers from ions $1 \mathrm{a} \mathrm{v}$. ion lifetime, calculated for $k_{\mathrm{H}}=5 \times 10^{5} \mathrm{~s}^{-1}, k_{\mathrm{D}}=1 \times 10^{5} \mathrm{~s}^{-1}$ and $\left.k_{f}=8 \times 10^{4} \mathrm{~s}^{-1}\right]^{\mathrm{b}}$ The relieved pattern corresponds to the loss of $C_{6}(H, D)_{6}$ in the 2 nd field-free region (FFR) of the ZAB-2F instrument (cf. Table 3 and Fig. 2(a)). 


\section{CONCLUSIONS}

Benzylbenzenium ions 1, generated by isobutane CI of diphenylmethane, undergo a slow interannular (ring-to-ring) proton exchange in competition to the fragmentation by loss of benzene. This is in sharp contrast to fast interannular proton exchange found in the higher homologues. A kinetic isotope effect $\left(k_{\mathrm{H}} / k_{\mathrm{D}}=5\right)$ operates during the interannular proton transfer in ions 1. A particularly high energy barrier towards this process is attributed to steric and entropic restrictions; it is estimated to be in the range of $50-75 \mathrm{~kJ} \mathrm{~mol}^{-1}$. Contrary to the interannular proton exchange, the intraannular proton exchange (proton ring-walk) is still very fast, giving rise to the random distribution of the protons at the benzenium ring.

\section{EXPERIMENTAL}

\section{Mass spectrometry}

The CI MIKE spectrometric measurements were performed using a ZAB-2F double-focusing instrument (VG Analytical Ltd) equipped with the combined $\mathrm{EI} / \mathrm{CI}$ ion source, working at $6 \mathrm{kV}$ (accelerating voltage), $100 \mathrm{eV}$ (electron energy), $0.5 \mathrm{~mA}$ (emission current), $180^{\circ} \mathrm{C}$ (source temperature), $3-7 \times 10^{-3} \mathrm{~Pa}$ (nominal source pressure). The diphenylmethane samples were introduced via the septum inlet heated to $150^{\circ} \mathrm{C}$. The isobutane used was of $>99.5 \%$ purity (Matheson). The ratio $\left[\mathrm{C}_{4} \mathrm{H}_{9}{ }^{+}\right] /$ $\left[\mathrm{C}_{3} \mathrm{H}_{7}{ }^{+}\right]$of the reagent gas ions was in the range of $3-5$. The data given in Table 2 represent average values from at least eight scans. The 'normal' $\mathrm{CI}$ mass spectra were measured using the $\mathrm{ZAB}-2 \mathrm{~F}$ and a Finnigan MAT $1020 \mathrm{~B}$ quadrupole instrument (values given in Table 1), the latter working at higher pressures of the $\mathrm{CI}$ reagent gas $\left(\left[\mathrm{C}_{4} \mathrm{H}_{9}{ }^{+}\right] /\left[\mathrm{C}_{3} \mathrm{H}_{7}^{+}\right] \sim\right.$ 10). For comparison, the CI mass spectra of 3 and 4 were measured with a $711 \mathrm{~A}$ instrument (Finnigan MAT) ${ }^{20}$ without significant change of the relative abundances of the $[\mathrm{M}+\mathrm{H}]^{+}$ions.

\section{Synthesis of the labelled diphenylmethanes}

The diphenylmethanes $\mathbf{3 a}, \mathbf{3 b}$ and $\mathbf{3 c}$ were obtained by the standard Grignard reaction of the appropriately labelled bromobenzene and benzaldehyde, followed by hydrogenolysis of the resulting benzhydrol. For the latter reaction, a mixture of $1.0 \mathrm{~g}$ of the deuterated benzhydrol, $60 \mathrm{ml}$ of methanol and $0.10 \mathrm{~g}$ of $\mathrm{Pd} / \mathrm{BaSO}_{4}(10 \%$, Merck) was shaken for $36 \mathrm{~h}$ in a Parr apparatus under hydrogen $\left(4 \mathrm{bar}, 25^{\circ} \mathrm{C}\right)$. Work-up and purification by Kugelrohr distillation afforded the corresponding diphenylmethane in $\sim 90 \%$ yield without significant loss of the deuterium label. This is in line with the high specificity of the catalytic deuterolysis of benzophenone reported in the literature. $^{21}$

Pentadeuterophenyl-phenyl-methanol was obtained from $3.0 \mathrm{~g}$ of pentadeuterobromobenzene (isotopic purity $>99 \%$, Merck) and $1.6 \mathrm{~g}$ of benzaldehyde in $70 \%$ yield after recrystallization from ether/petroleum ether; m.p. 67-68 ${ }^{\circ} \mathrm{C} ;{ }^{1} \mathrm{H}-\mathrm{NMR}$ (Bruker WP 80, $\left.\mathrm{CDCl}_{3} / \mathrm{TMS}\right): \quad \delta 2.25(\mathrm{~d}, J=3.3 \mathrm{~Hz}, \quad 1 \mathrm{H}), \quad 5.80(\mathrm{~d}$, $J=3.3 \mathrm{~Hz}, 1 \mathrm{H}), 7.3(\mathrm{~s}, \sim 5 \mathrm{H})$.

Pentadeuterophenyl-phenyl-methane (3a) was obtained as an oil; ${ }^{1} \mathrm{H}-\mathrm{NMR}\left(\mathrm{CDCl}_{3}\right): 3.96(\mathrm{~s}, 2.0 \mathrm{H}), 7.2(\mathrm{~s}$, $\leq 5.5 \mathrm{H}$ ). According to the ${ }^{1} \mathrm{H}-\mathrm{NMR}$ and $\mathrm{CI}$ (iso$\mathrm{C}_{4} \mathrm{H}_{10}$ ) mass spectra, the isotopic purity of $\mathbf{3 a}$ was $>96 \%\left(>90 \% \mathrm{~d}_{5}\right)$.

Phenyl-(3,4,5-trideuterophenyl)-methanol was obtained using $2.5 \mathrm{~g}$ of 1-bromo-3,4,5-trideuterobenzene $\mathrm{e}^{22}$ $\left(94.1 \% \mathrm{~d}_{3}, 5.7 \% \mathrm{~d}_{2}, 0.3 \% \mathrm{~d}_{1}\right)$. The trideuterated benzhydrol was purified by chromatography (silica gel $/ \mathrm{CHCl}_{3}$ ) to give a yield of $61 \%$; m.p. $65-67^{\circ} \mathrm{C}$; ${ }^{1} \mathrm{H}-\mathrm{NMR}\left(\mathrm{CDCl}_{3}\right): 2.26(\mathrm{~d}, J=3.2 \mathrm{~Hz}, 1 \mathrm{H}), 5.81(\mathrm{~d}$, $J=3.2 \mathrm{~Hz}, 1 \mathrm{H}), 7.2-7.4(\mathrm{~m}, \sim 7 \mathrm{H})$.

Phenyl-(3,4,5-trideuterophenyl)-methane (3b) was obtained as an oil; ${ }^{1} \mathrm{H}-\mathrm{NMR}\left(\mathrm{CDCl}_{3}\right): 3.95(\mathrm{~s}, 2.0 \mathrm{H})$, $7.1-7.2(\mathrm{~s},<7.3 \mathrm{H})$. According to the ${ }^{1} \mathrm{H}-\mathrm{NMR}$ and the $\mathrm{CI}$ (iso- $\mathrm{C}_{4} \mathrm{H}_{10}$ ) mass spectra, the isotope purity of 3b was $>95 \%\left(>90 \% \mathrm{~d}_{3}\right)$.

Phenyl-(2,4,6-trideuterophenyl)-methanol was obtained using $2.4 \mathrm{~g}$ of 1-bromo-2,4,6-trideuterobenzene ${ }^{23}$ $\left(97.3 \% \mathrm{~d}_{3}, 2.3 \% \mathrm{~d}_{2}, 0.4 \% \mathrm{~d}_{1}\right)$. This trideuterated benzhydrol was purified as described above (67\% yield); m.p. $65-67^{\circ} \mathrm{C} ;{ }^{1} \mathrm{H}-\mathrm{NMR}\left(\mathrm{CDCl}_{3}\right): 2.30($ br s, $1 \mathrm{H})$, 5.75(br s, $1 \mathrm{H}), 7.2-7.4(\mathrm{~m},>7.2 \mathrm{H})$.

Phenyl-(2,4,6-trideuterophenyl)-methane (3c) was obtained as an oil; ${ }^{1} \mathrm{H}-\mathrm{NMR}\left(\mathrm{CDCl}_{3}\right): 3.98(\mathrm{~s}, 2.0 \mathrm{H})$. 7.23 (br s, $\geqslant 5 \mathrm{H}$ ), 7.28(br s, $\geq 2 \mathrm{H}, \mathrm{H}^{3}$ and $\mathrm{H}^{5}$ ). According to the ${ }^{1} \mathrm{H}-\mathrm{NMR}$ and the $\mathrm{CI}\left(\right.$ iso- $\left.\mathrm{C}_{4} \mathrm{H}_{10}\right)$ mass spectra, the isotopic purity of $3 c$ was $>95 \%$ $\left(>90 \% \mathrm{~d}_{3}\right)$.

$\boldsymbol{\alpha}, \boldsymbol{\alpha}$-Dideutero-diphenylmethane (3d) was prepared by reduction of benzophenone with $\mathrm{LiAlD}_{4} / \mathrm{AlCl}_{3}$ according to a procedure given in the literature. ${ }^{24,11 a}$ The isotopic purity was $>98 \% ;{ }^{1} \mathrm{H}-\mathrm{NMR}\left(\mathrm{CDCl}_{3}\right)$ : $3.95(<0.03 \mathrm{H}), 7.3(\mathrm{~s}, 10 \mathrm{H}) .^{11 \mathrm{a}}$

\section{Acknowledgements}

We thank Dr K. D. Klöppel, Universität Siegen, FRG, for measuring CI mass spectra of 3 and 4 with the Finnigan MAT 711 A instrument. Technical assistance by $\mathrm{Mr} \mathrm{E}$. Gärtner and $\mathrm{Mr} \mathrm{G}$. Lipinski is greatfully acknowledged, as well as financial support of this work by the 'Forschungsprojekt 2196', Universität Bielefeld. Thanks are also due to Prof. H. F. Grützmacher for his continuous interest and support of this work. 


\section{REFERENCES}

1. (a) V. A. Koptyug, Top. Curr. Chem. 122, 1 (1984); (b) V. G. Shubin, Top. Curr. Chem. 116/117, 267 (1984); (c) P. Ahlberg, G. Jönsall and C. Engdahl, Adv. Phys. Org. Chem. 19, 223 (1983); (d) D. M. Brouwer, E. L. Mackor and C. MacLean, in Carbonium lons, ed. by G. A. Olah and P. v. R. Schleyer, Vol. 2, Chapt. 20, Wiley, New York (1970).

2. G. A. Olah, J. S. Staral, G. Ascencio, G. Liang, D. A. Forsyth and G. D. Mateescu, J. Am. Chem. Soc. 100, 6299 (1978).

3. D. Farçasiu, M. T. Melchior and L. Craine, Agnew. Chem. 89, 323 (1977), Angew. Chem., Int. Ed. Engl. 16, 315 (1977).

4. A. P. Bruins and N. M. M. Nibbering, Org. Mass Spectrom. 11, 950 (1976).

5. D. Kuck, Int. J. Mass Spectrom. Ion Phys. 47, 499 (1983); this paper contains a preliminary report on the present results.

6. D. Kuck, J. Schneider and H.-F. Grützmacher, J. Chem. Soc., Perkin Trans. 2689 (1985)

7. (a) D. Kuck, W. Bäther and H. F. Grützmacher, J. Am. Chem. Soc. 101, 7154 (1979); (b) D. Kuck, W. Bäther and H.-F. Grützmacher, Int. J. Mass Spectrom. Ion Proc. 67, 75 (1985); (c) W. Bäther, D. Kuck and H.-F. Grützmacher, Org. Mass Spectrom. 20, 589 (1985).

8. D. Kuck, H. F. Grützmacher, S. Ingemann, L. de Koning and N. M. M. Nibbering, Angew. Chem. 97, 691 (1985), Angew. Chem., Int. Ed. Engl. 24, 693 (1985).

9. (a) W. Bäther and H.-F. Grützmacher, Int. J. Mass Spectrom. Ion Proc. 64, 193 (1984); (b) W. Bäther, D. Kuck and H.-F. Grützmacher, Org. Mass Spectrom. 20, 572 (1985).

10. (a) Y. Yamamoto, S. Takamuku and H. Sakurai, J. Am. Chem. Soc. 94, 661 (1972), and previous work; (b) J. Shen R. C. Dunbar and G. A. Olah, J. Am. Chem. Soc. 96, 6227 (1974), and work cited there; (c) J.-L. M. Abboud, W. J. Hehre and R. W. Taft, J. Am. Chem. Soc. 98, 6072 (1976).

11. (a) U. Neuert, Doctoral theses, University of Hamburg (1975); (b) T. K. Bradshaw, J. H. Bowie and P. Y. White, J. Chem. Soc., Chem. Commun. 537 (1970).

12. W. Bäther, Doctoral thesis, University of Bielefeld (1984)

13. R. G. Cooks, J. H. Beynon, R. M. Caprioli and G. L. Lester, Metastable lons, Chapt. 4. Elsevier, Amsterdam (1973).

14. E. E. Kingston, J. S. Shannon, V. Diakiw and M. J. Lacey,
Org. Mass Spectrom 16, 428 (1981).

15. The energetic preference of a collinear orientation of the donor $X-H$ bond and the acceptor $Y$ atom has been postulated for $\mathrm{H}$ atom transfer reactions; see $\mathrm{J}$. W. Wilt, in Free Radicals, ed. by J. K. Kochi, Vol. 1, p. 333ff. Wiley-Interscience, New York (1973).

16. C. Köppel, C. C. van de Sande, N. M. M. Nibbering, T. Nishishita and F. W. McLafferty, J. Am. Chem. Soc. 99, 2883 (1977).

17. Heats of formation ( $\left.\mathrm{kJ} \mathrm{mol}^{-1}\right)$ used in the present work: $\left[\mathrm{C}_{6} \mathrm{H}_{5} \mathrm{CH}_{2}\right]^{+}+883$ (F. A. Houle and J. L. Beauchamp, J. Am. Chem. Soc. 100, 3290 (1978)); $\left[\mathrm{C}_{6} \mathrm{H}_{5} \mathrm{CH}_{2} \mathrm{CH}_{2}\right]^{+}+1030$ (Ref. 9a); $\left[\mathrm{C}_{6} \mathrm{H}_{5} \mathrm{CHCH}_{3}\right]^{+}+860$ (R. G. McLoughlin, J. D. Morrison and J. C. Traeger, Org. Mass Spectrom. 14, 104 (1979)); (benzene +83 ) (J. L. Franklin, J. G. Dillard, H. M. Rosenstock, J. T. Herron, K. Draxl and F. H. Field, Ionization Potentials, Appearance Potentials, and Heats of Formation of Gaseous Positive lons, Natl. Stand. Ref. Data Ser. 26 , Nat. Bur. Stand., Washington, District of Columbia (1969)). This reference has been used to calculate $\Delta H_{4}(3)=+163$ and $\Delta H_{f}(4)=+142$ using increments. $\Delta H_{f}(1)$ and $\Delta H_{f}(2)$ have been estimated using $P A(n$-butylbenzene $)=$ $816 \mathrm{~kJ} \mathrm{~mol}^{-1}$ (D. H. Aue and M. T. Bowers, in Gas Phase Ion Chemistry, ed. by M. T. Bowers, Vol. 2, Chapt. 9. Academic Press, New York (1979)).

18. D. Heidrich, M. Grimmer and B. Sommer, Tetrahedron 32 , 2027 (1976); see also references given therein.

19. Somewhat different values for the local PAs of toluene have been obtained experimentally: J. L. Devlin III, J. F. Wolf, R. W. Taft and W. J. Hehre, J. Am. Chem. Soc. 98, $1990(1976)$.

20. K. D. Klöppel, personal communication.

21. S. E. Scheppele, R. K. Mitchum, J. W. Burnham, E. J. Eisenbraun and P. W. Flanagan, J. Catal. 19, 89 (1970).

22. D. Kuck and H. F. Grützmacher, Org. Mass Spectrom. 13, 90 (1978).

23. (a) F. Langenbucher, R. Mecke and E. D. Schmid, Liebigs Ann. Chem. 669, 11 (1963); (b) D. H. Williams, S. W. Tam and R. G. Cooks, J. Am. Chem. Soc. 90, 2150 (1968).

24. R. F. Nystrom and C. R. A. Berger, J. Am. Chem. Soc. 80, 2896 (1958). 